\title{
A praça colonial brasileira
}

Junia Marques Caldeira ${ }^{11}$

\section{Resumo}

O presente artigo tem como objetivo central investigar a origem de um dos principais elementos compositivos do espaço urbano: a praça brasileira. $\mathrm{O}$ ponto de partida, deste processo, é a colonização portuguesa, que ocorre simultaneamente em diversas cidades nos séc. XV a XVII. Esse processo de desenvolvimento urbano foi notadamente marcado pelas referências do urbanismo português e, no caso da praça, apresenta uma diversidade de modelos que ainda estão presentes na paisagem urbana das cidades brasileiras. Neste contexto, o artigo analisa casos específicos que exemplificam a formação da praça colonial no Brasil, tais como o primeiro modelo de praça cívica brasileira, na cidade de Salvador, e o Paço Real, espaço-símbolo na vida da corte brasileira, na cidade do Rio de Janeiro. Essas praças, com seus edifícios históricos, formam um significativo acervo e preservam os conjuntos arquitetônicos das cidades coloniais, permitindo ao público compreender sua origem e suas transformações nos últimos séculos. Estudar a trajetória de um espaço urbano não se resume a um exercício cronológico de momentos urbanos. $\mathrm{O}$ ambiente urbano representa um espaço em permanente transformação, conformado como um "depositário" de sucessivas camadas simbólicas. Portanto, pensar no conceito de praça é também resgatar símbolos presentes em nossa memória urbana, que definem padrões espaciais ou que apontam para modelos mais frequentes.

Palavras-chave: Praça. Espaço público. Cidades Coloniais.

1 Graduada em Arquitetura e Urbanismo na Universidade Federal de Minas Gerais, doutora pelo Programa de pós-Graduação em História do Instituto de Filosofia, Ciências e História da Universidade Estadual de Campinas. Professora de Teoria e História, Projeto Urbano e de Arquitetura no UniCEUB, Brasília, DF. Email: juniacald@gmail.com 


\section{Introdução}

Todas as cidades, grandes ou pequenas, têm sempre uma praça onde aconteceram fatos que, pela sua importância, trazem para aquela área um valor histórico bem maior do que o representado pela sua função urbana (MARCOS TAMOIO apud FERREZ, 1978).

Conceitualmente, a praça, apesar de assumir papéis distintos e apresentar uma diversidade morfológica, possui em sua gênese o caráter de espaço coletivo lugar de manifestação de culto e de ritos propícios à interação social. Na Antiguidade greco-romana, a praça era o espaço público de maior importância da cidade e funcionava como seu centro vital. Materializada na figura da Ágora ou do Fórum, a praça, com seu conjunto arquitetônico era o locus publicci da vida citadina. $\mathrm{Na}$ cultura ocidental, as praças desempenharam um papel importante no contexto urbano: são espaços referenciais, atuando como marcos visuais e como pontos focais na organização da cidade (ZUCKER, 1959, p. 2).

A colonização do Novo Mundo resultou na formação de espaços que refletem as influências urbanísticas das culturas colonizadoras. No continente sul-americano o domínio espanhol e português constituiu diferentes morfologias urbanas, cujas marcas estão presentes no modo de apropriação dos territórios. Nesse contexto, as cidades constituem reflexos do modo distinto e particular de desenvolvimento da política colonial empreendida pelas metrópoles.

No Brasil, desde a formação dos primeiros núcleos urbanos, a herança do urbanismo português fez-se presente. As vilas e cidades foram constituindo-se com base em características precisas de uso e ocupação do território, apoiadas na tradição portuguesa. Analisar esta tradição nos permite investigar qual o papel desempenhado pelo espaço da praça na estrutura urbana e estabelecer uma conexão com o desenvolvimento das praças brasileiras.

Referência no estudo da história urbana das cidades lusitanas, Manuel C. Teixeira ${ }^{2}$ é responsável pela investigação sobre a formação da praça nas cidades

2 Manuel C. Teixeira, arquiteto, professor, foi presidente da Comissão Científica de Arquitetura e Urbanismo do ISCTE e Coordenador Científico do Mestrado em Desenho Urbano e da 
portuguesas, explorando notadamente o período quinhentista. Tomando como base seu estudo, este artigo busca compreender a influência do urbanismo português no desenvolvimento da praça brasileira durante o processo de colonização.

\section{Antecedentes portugueses}

O processo de formação da praça brasileira está diretamente relacionado aos princípios urbanísticos da tradição portuguesa utilizados na colonização da América. Estudando o urbanismo português e sua influência ultramarina, Teixeira (2000) identifica a existência de padrões que aparecem na "estrutura global da cidade". Esses padrões estão presentes desde a escolha topográfica dos sítios e do traçado, até a constituição dos elementos morfológicos - quarteirões, lotes, ruas, praças -, resultando em certa composição arquitetônica. Embora se observe a presença dessas características nas cidades coloniais brasileiras, não ocorreu uma transposição direta desses modelos urbanos, mas sim uma adaptação às novas condições da Colônia.

A praça, como elemento morfológico, está notadamente vinculada à formação do núcleo urbano. Sua estrutura tem origem na composição formal de elementos como vias, ruas principais, traçado, casario, edificações institucionais, muralhas, entre outros, mas está sujeita também aos aspectos sociais que envolvem a hierarquia, o uso e a forma de apropriação pela sociedade em cada época (PAIO apud TEIXEIRA, 2001, p. 36).

O desenvolvimento urbanístico português sofreu grande impulso com a necessidade de criação de vilas e núcleos urbanos para o povoamento das colônias ultramarinas, ocorrido a partir do séc. XV. Esse processo serviu como laboratório para implementar novas diretrizes urbanas que, posteriormente, constituíram parâmetros morfológicos e urbanísticos.

Licenciatura em Arquitetura do ISCTE. Realiza pesquisas na área de história urbana, tendo recentemente se dedicado ao projeto "As morfologias urbanas da cidade portuguesa". De sua autoria destacam-se: O urbanismo português, séculos XIII-XVIII. 1999; A história urbana em Portugal: desenvolvimentos recentes, 1988; As praças urbanas portuguesas quinhentistas. In: Colóquio Portugal-Brasil. A praça na cidade portuguesa, Lisboa, 2001. Coordenador. 
Na história do urbanismo português, Teixeira (2000, p. 1) observa que o desenvolvimento das cidades tem origem em duas vertentes: uma vernácula, tradicional, apoiada nos processos de formação característicos das cidades medievais, e outra erudita, cujas bases fundamentaram-se na concepção de sistemas ortogonais. A tradição vernacular predominou a partir do séc. XIII, quando as principais cidades portuguesas passaram por um processo de rápido desenvolvimento. A vertente erudita, cuja principal característica corresponde à racionalização e à regularização dos traçados urbanos, manifesta-se na formação das cidades a partir do séc. XVI. Essa última vertente comparece, sobretudo, nas cidades coloniais brasileiras cuja formação espacial esteve sujeita às orientações determinadas pela Corte Portuguesa.

Na identificação dessa herança, independentemente da vertente que constitui o traçado urbano, existem especificidades que se tornaram marca registrada das cidades portuguesas, como por exemplo, o respeito e a interação com a geografia e a topografia do sítio original. Teixeira (2000, p. 2) afirma que em "todos os tempos, quer se desenvolva gradualmente ou de acordo com um plano pré-definido, a cidade portuguesa é planeada e projectada no sítio, e com o sítio, atendendo de perto às características do território em que se implanta”.

Essa especificidade do processo de formação de cidades gerou uma maior diversidade de traçados urbanos na América portuguesa, estabelecendo diferenças fundamentais com o traçado quadriculado, ou em tabuleiro, empreendido nas cidades da América Espanhola. Ademais, foi justamente essa diversidade que propiciou a riqueza paisagística encontrada nas cidades coloniais do território português ultramarino. ${ }^{3}$

\footnotetext{
3 O respeito ao sítio original, marca da ordenação espacial portuguesa, deu margem a interpretações de autores como Sérgio Buarque de Holanda e Robert Smith, que concluíram que no processo de formação das cidades brasileiras não houve um planejamento prévio, como as espanholas, acarretando um desenho mais espontâneo. Pesquisas recentes tendem a admitir a presença de distintos fatores na constituição da América Espanhola e da Portuguesa, porém anulam qualquer oposição centrada na questão do traçado urbano, vinculado ao conhecimento e aplicação dos parâmetros presentes nas Leis das Índias. Sobre esse assunto ver: Reis Filho (1968), Delson, M. (1997), Rossa, W. (1998) e Teixeira, M.(2001).
} 
Figura 1 - Cidade de San Domingo, 1671.

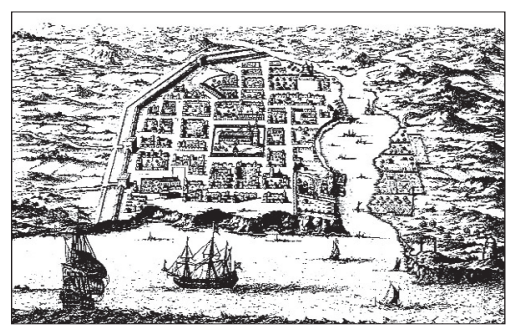

A planta em "xadrez" representa um típico traçado espanhol

Fonte: Historia de la forma urbana (MORRIS, 1992).

A adaptação do traçado urbano às características naturais dos terrenos acidentados acarretou outra questão na formação das cidades brasileiras: o descompasso entre o uso do traçado racional sob uma topografia irregular. A cidade de Salvador ilustra bem tal situação: embora tenha sido aplicado o traçado quadriculado, a topografia do sítio dificulta a leitura da vertente racional, sobressaindo-se na paisagem ladeiras e morros.

Figura. 2 - Planta da cidade de "São Salvador", 1615 e perfil da cidade.
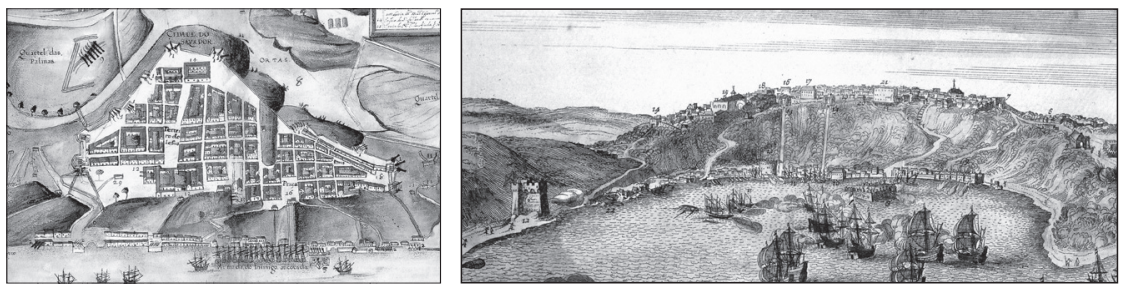

Traçado regular adaptado à topografia - cidade baixa e cidade alta.

Fonte: Imagens de vilas e cidades do Brasil-Colonial (REIS FILHO, 2000).

O processo de formação da praça portuguesa ocorreu gradualmente e sua consolidação correspondeu, na maioria dos casos, ao próprio processo de desenvolvimento das cidades. Segundo Teixeira (2001, p. 69), somente a partir do séc. XIV é que se inicia a conformação de praças

A praça urbana só lentamente se implanta na cultura urbanística portuguesa. No início de muitos aglomerados urbanos portugueses, incluindo muitas cidades medievais planeadas, não existiam praças rigorosamente estruturadas. Os espaços que cumpriam estas funções eram habitualmente 
espaços marginais à estrutura urbana, localizados junto às portas ou adjacentes às muralhas.

A estruturação da praça esteve sujeita aos mesmos processos ocorridos no contexto urbano português e resultou na criação de espaços diversificados, originados a partir de dois princípios: a praça espontânea, presente no universo medieval, e a praça formal, gerada a partir da aplicação de princípios racionais (TEIXEIRA, 2001, p. 71).

Em fins do séc. XV, observou-se uma nova postura em relação às cidades, traduzida no "entendimento dos espaços urbanos como palco de manifestações culturais". Esse entendimento foi seguido por uma nova conduta por parte dos dirigentes, cujos objetivos visavam à implantação de um processo de modernização do espaço urbano e arquitetônico. ${ }^{4}$

Esse movimento de modernização transformou o espaço da praça no foco principal dos projetos de intervenção e reforma, de alteração e expansão de cidades, destacando de maneira inédita o modelo de "praças urbanas regulares". A partir desse momento, estabeleceu-se uma mudança no status da praça: o espaço adquiriu importância como elemento formal, tornando-se marco central na estrutura urbana.

Analisando as reformas dos espaços públicos portugueses, Rossa (2001) destaca que, juntamente com o processo de valorização estética da praça, muitas cidades tiveram a oportunidade de associar às intervenções a reconstrução de

\footnotetext{
4 Segundo Teixeira (2001, p.71) o processo de modernização das cidades iniciou-se com a implantação do Código de Leis e Forais, no séc. XIII. Essas codificações deram origem às Ordenações Afonsinas e Manuelinas, cujo conteúdo incluía desde questões sobre abastecimento público, ofícios artesanais e públicos, limpeza e saúde pública, festas, realização de obras, até diretrizes construtivas.
} 
edifícios institucionais e religiosos, como Casas de Câmara, Igrejas Matrizes e Misericórdias (hospitais). Essa nova praça, conformada por um conjunto arquitetônico relevante, tornara-se palco para abrigar esses novos monumentos.

Os "rossios", "terreiros" ou "largos" junto às portas das cidades, por regra sempre exteriores [...], foram gradualmente reformados em praças onde freqüentemente se construiu de novo a casa da Câmara, o quase inseparável açougue e se ergueu o pelourinho. São espaços, equipamentos ou instituições velhos com novo significado, atribuições e poder, símbolos de um Estado já bem enraizado (ROSSA, 2001, p. 50).

O modelo de praça desenvolvido nessas intervenções baseou-se não apenas na valorização dos aspectos estéticos, mas também nos aspectos simbólicos e funcionais. Esses projetos de reestruturação urbana visavam à constituição de um cenário marcante, destacado pelos edifícios e pelas funções que desempenhavam no conjunto urbano. Essas praças cumpriam o papel de marco urbano, de ponto de referência na estrutura da paisagem e, em função dessas características, ainda permanecem como espaços simbólicos na atualidade (TEIXEIRA, 2001, p. 77).

Inúmeros são os exemplos de praças que se originaram dessa conformação. ${ }^{5}$ A Praça da República, na cidade de Viana do Castelo, bem como o Largo da Sé na cidade de Funchal representam modelos típicos. ${ }^{6}$

5 Teixeira (2001, p.72) afirma que esse processo de estruturação de praças atingiu principalmente as cidades de origem portuária, em virtude do crescimento e da expansão comercial. Cita Lisboa, Porto, Setúbal, Lagos, Aveiro, Viana do Castelo, como exemplos litorâneos, Niza, Elvas e Beja, como cidades do interior que receberam praças novas, e cidades como Funchal e Ponta Delgada, nas Ilhas atlânticas da Madeira e dos Açores, que tiveram parte da cidade reestruturada.

6 Os espaços públicos mais significativos como o Poço, o Mercado, a Praça de Armas e a Torre de Menagem situavam-se, inicialmente, na área vazia entre o núcleo e a muralha. A construção da Matriz e do hospital formou o primeiro conjunto urbano, no séc. XV: a Praça Central (atual Praça Velha) 
Figura. 3 - Praça da República, Antiga praça do campo, Viana do castelo.

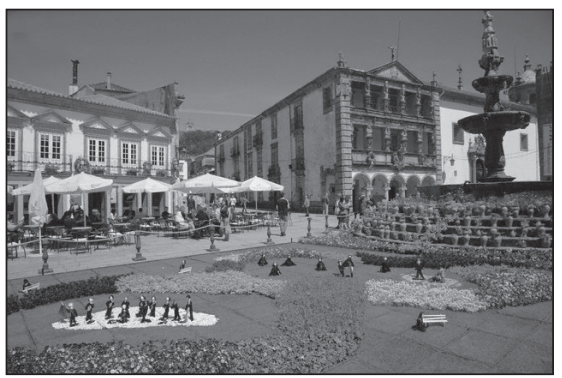

Fonte: www.corbis.com - set. 2007.

Figura 4 - Largo da Sé, atual praça do município - cidade do Funchal.

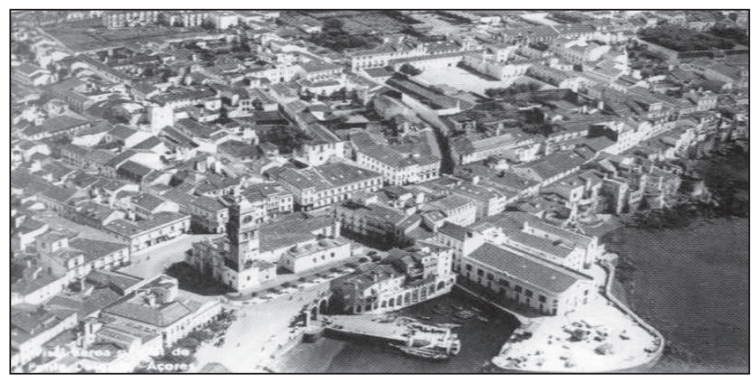

Fonte: www.indispensaveis.blogspot.com - mar. 2006

Como pontos de articulação urbanística e arquitetônica, as praças reuniam as principais edificações institucionais da cidade propiciando a formulação de vários modelos para abrigar funções e atividades diferentes. A configuração desses conjuntos urbanos consolidou um padrão urbanístico que se implantou na maioria das cidades coloniais brasileiras: espaços distintos de caráter cívico, religioso e comercial.

É habitual encontrarem-se nas praças portuguesas diferentes praças para diferentes funções: função de mercado, em espaços que muitas vezes tinha sua origem em campos e em terreiros localizados à margem das malhas urbanas [...]; funções militares, nomeadamente os campos associados às torres de menagem medievais e as praças de armas seiscentistas; funções políticas e administrativas, em que se incluem as praças associadas ao poder municipal, onde se localizavam a Casa de Câmara e o pelourinho; funções religiosas (TEIXEIRA, 2001, p. 11). 
No entanto, não apenas a função distingue a influência portuguesa na formação da praça brasileira, seu desenho esboça uma variedade formal bastante distinta da Plaza Mayor, encontrada nas cidades da colonização espanhola. Conformada normalmente pela supressão de um módulo da quadrícula, a Plaza Mayor era cercada por 12 ruas distribuídas da seguinte maneira: "de La Plaza salgan quatro calles principales, una por medio de cada costado; y demas de estas dos por cada esquina. ${ }^{7}$ A disposição urbana variava de acordo com a situação geográfica do povoado a ser fundado. ${ }^{8}$ A localização central era a mais frequente (Santiago do Chile), porém encontra-se também a disposição lateral (Buenos Aires). Normalmente constituía a única praça da cidade.

\section{Figura 5 - Planta da cidade de Santiago do Chile ao centro a Plaza Mayor.}

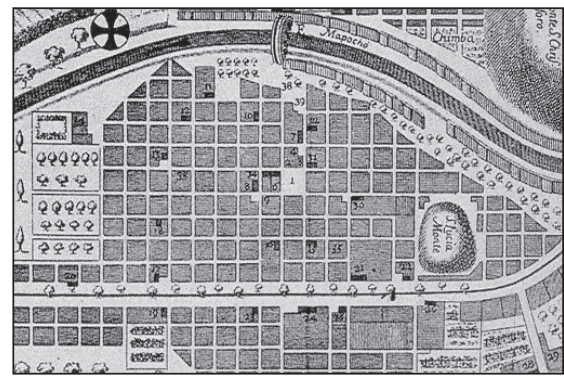

Fonte: www.auroradechile.cl - dez. 2005.

Essa diferença pode ser comprovada nas cidades coloniais brasileiras, onde encontramos uma maior diversidade de praças, tanto nos aspectos estéticos quanto nos aspectos morfológicos e funcionais. O processo de formação da cidade de Salvador constituiu um exemplo típico de desenvolvimento de espaços multifuncionais. A análise da planta da cidade, elaborada em 1615, revela a existência de dois vazios que correspondem aos principais conjuntos urbanos: a Praça da Câmara e o Terreiro de Jesus.

7 Para maiores detalhes ver: Lei Lviiij. "Que el sitio, tamaño y disposicion de la plaza sea como se ordena”. Ordenanza 112, 113, 114 y 115. (LEYES DAS ÍNDIAS apud SANTOS, 2000).

8 Ver: Lei das Índias abaixo: "Lviiij. "Que el sitio, tamaño y disposicion de la plaza sea como se ordena". Ordenanza 112, 113, 114 y 115. "La Plaza mayor donde se ha de comenzar la poblacion, siendo en Costa de Mar, se debe hacer al desembarcadero del puerto, y si fuere lugar mediterranea, en medio de la poblacion". (LEYES DAS ÍNDIAS apud SANTOS, 2000). 
Figura 6 - Planta da cidade de Salvador, 1715

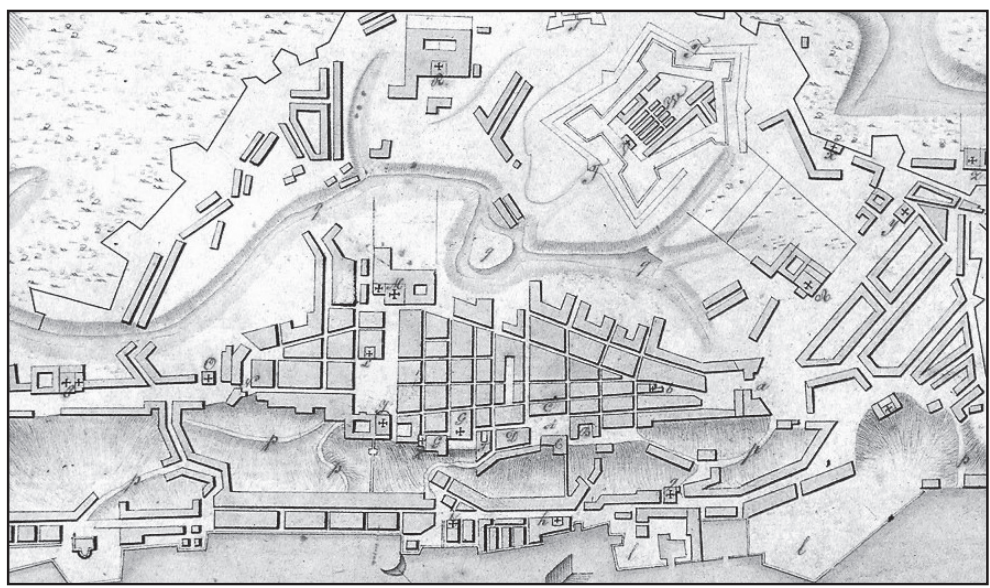

Em destaque o Terreiro de Jesus (à esquerda) e a praça da Camara (à direita).

Fonte: Imagens de vilas e cidades do Brasil Colonial (REIS FILHO, 2000).

O conjunto formado pela Praça da Câmara constituía o núcleo social mais importante da cidade e, segundo Marx (1980, p. 51), representou a primeira praça cívica brasileira. Apresentava um centro administrativo, onde se "reunia a Casa de Câmara e Cadeia, o paço do governador da colônia, a Relação, os negócios da fazenda e a alfândega. No centro da nova cidade projetada, a praça marcava urbanisticamente o seu caráter de capital." No seu espaço, ocorriam festividades cívicas e religiosas, encenações, paradas e desfiles. ${ }^{9}$

Inicialmente denominada de Praça da Câmara, esse espaço desenvolveu a função de mercado, abrigando semanalmente uma feira, passando a chamar-se Praça da Feira. As diversas funções assumidas posteriormente pela praça influenciaram diretamente sua toponímia. Foi Praça de Mercado, Praça da Cidade, Praça da Parada, Praça do Palácio, Praça do Conselho e, em 1828, tornou-se Praça Municipal.

\footnotetext{
9 A presença do pelourinho (removido em 1618) reforçava sua importância no cotidiano da população. O Estado, contrapondo-se ao poder religioso, marca sua entrada oficial na cidade com a instalação do pelourinho. Diante da necessidade de estabelecer mecanismos de controle no regime escravocrata, criou-se um espaço onde se realizavam punições públicas: os condenados, amarrados ao poste, ficavam expostos à execração pública.
} 
A praça era aberta para o lado da baía, enquadrando a paisagem do mar e o horizonte. O cronista Gabriel Soares de Souza assim a descreve em fins do séc. XVI:

Está no meio desta cidade uma honesta praça, em que se correm touros quando convém em a qual estão da banda do sul umas nobres casas, em que se agasalham os governadores, e da banda do norte tem as casas do negócio da Fazenda, da alfândega e armazéns; e da parte leste tem a casa da câmara, cadeia e outras casas de moradores, com que fica esta praça em quadro e o pelourinho no meio dela, a qual a banda do poente está desabafada com grande vista sobre o mar onde estão assentadas algumas peças de artilharia grossa, donde a terra vai muito a pique sobre o mar ao longo do qual é tudo rochedo mui áspero (SOUZA apud FLEXOR, 2001, p. 105).

Em termos formais, a Praça da Câmara representou o modelo de praça colonial aberta. Sua conformação esboça a organização e a estrutura urbana das primeiras cidades coloniais litorâneas, cuja proximidade com a área portuária reforçava seu caráter de centro dominante na malha urbana. Situada na encosta e voltada para o mar, esse modelo reflete o momento político de dependência da metrópole portuguesa e a importância das relações.

Figura 7 - Vista da praça municipal de salvador.

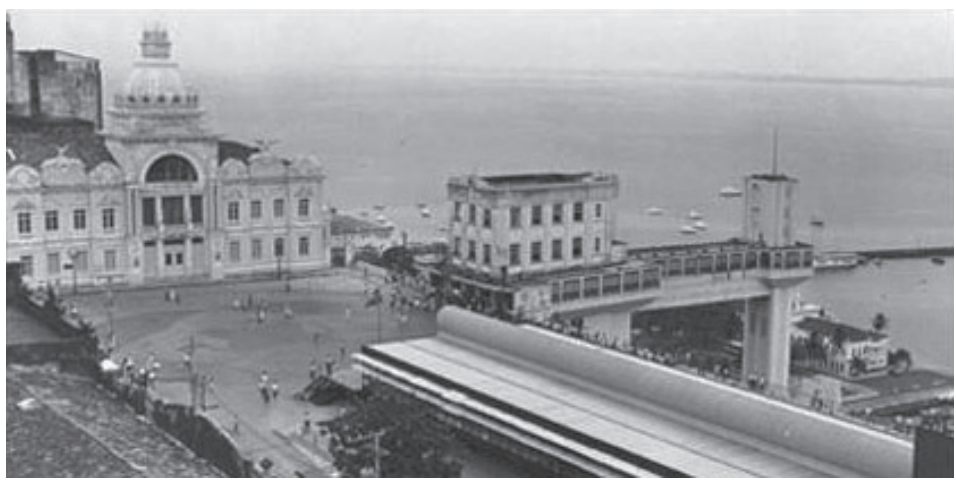

Fonte:www.macalester.edu/.../ Templates/history.htm - jan. 2000.

A configuração dos espaços de caráter religioso aparece na formação dos chamados largos, terreiros, adros e campos. Simbolizam a presença das diversas ordens religiosas existentes no contexto urbano português e que desempenharam um papel importante na colonização brasileira. Segundo Marx (1980, p. 54), "uma 
igreja, uma praça; regra geral nas nossas povoações antigas". Na maioria das vezes, essas praças tornavam-se o centro vital da cena urbana: os "templos, seculares ou regulares, raramente eram sobrepujados em importância por qualquer outro edifício, nas freguesias ou nas maiores vilas. Congregavam os fiéis, e os seus adros reuniam em torno de si as casas, as vendas e quando não o Paço da câmara”. São espaços adjacentes à entrada da Igreja, delimitados, ou não, por uma pequena mureta. Denominações como Praça Matriz, Terreiro de Jesus, Largo do Carmo, Largo São Francisco ou Praça da Sé indicam a diversidade de praças religiosas que constituíram nossa paisagem urbana.

Na cidade de Salvador, o Terreiro de Jesus formava o segundo conjunto urbano mais importante da nascente cidade. Estava localizada em frente ao Colégio dos Jesuítas. Suas qualidades também foram destacadas por Gabriel Soares de Souza ao descrever a cidade:

[...] um terreiro mui bem assentado e grande, aonde se representam as festas a cavalo, por ser maior que a praça, o qual está cercado de nobres casas. E ocupa este terreiro e parte da rua da banda do mar um suntuoso colégio dos padres da Companhia de Jesus, com uma formosa e alegre igreja, onde se serve o culto divino" (SOUZA apud REIS FILHO, 2000, p. 137).

Figura 8 e 9 - Terreiro de Jesus ("Exéquias dos Reis de Portugal") 1908 e situação atual. Sua configuração original permanece quase intacta.
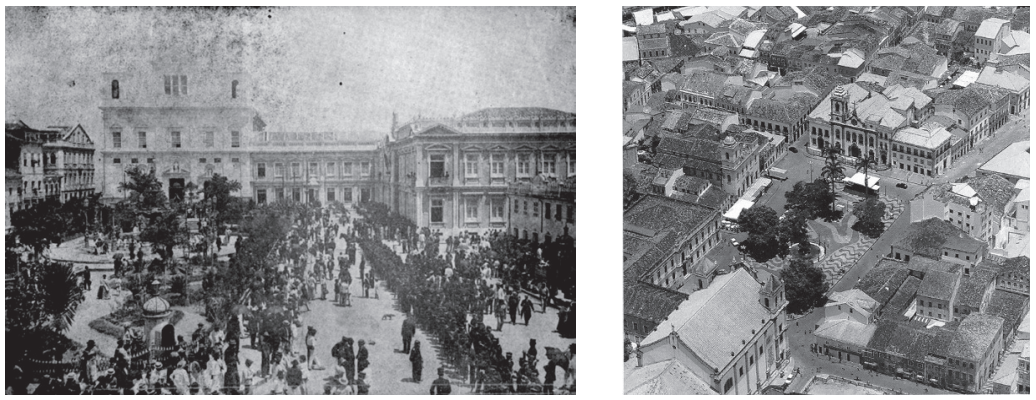

Fonte: www.cidteixeira.com.br - jan. 2007

e Patrimônios da Humanidade no Brasil (TIRAPELLI, 2001)

A partir do séc. XVII, o modelo de praça formal aparece não apenas nas cidades portuguesas, mas também nas cidades ultramarinas, onde a rigidez da 
malha urbana, ditada pelas Cartas Régias e pelos Autos de Fundação, constituiu um espaço regular, geralmente centralizado na estrutura da cidade e por onde se desenvolveu o traçado. Segundo Teixeira (2001, p. 83), essa praça apresenta-se de forma quadrada ou retangular e assume, desde sua formação, o papel de centro formal e funcional da cidade:

Nestas novas fundações, uma praça ou, freqüentemente, duas praças, de forma quadrada ou retangular e localizadas no centro da povoação constituíam o elemento gerador da estrutura física da cidade. Era a partir delas que se definia o traçado das ruas, e se estruturavam o conjunto da malha urbana, geralmente segundo um sistema ortogonal. Quando se tratava de uma única praça, era nela que se localizava a Igreja, a casa de Câmara e Cadeia e o pelourinho. Quando existiam duas praças, elas destinavam-se a funções distintas. Enquanto numa se localizava a Casa de Câmara e Cadeia e era centrada no pelourinho, na outra localizava-se a Igreja, com o cruzeiro no centro.

\section{Figura 10 - Praça Marques de Pombal - Vila Real de Santo Antonio, Portugal.}

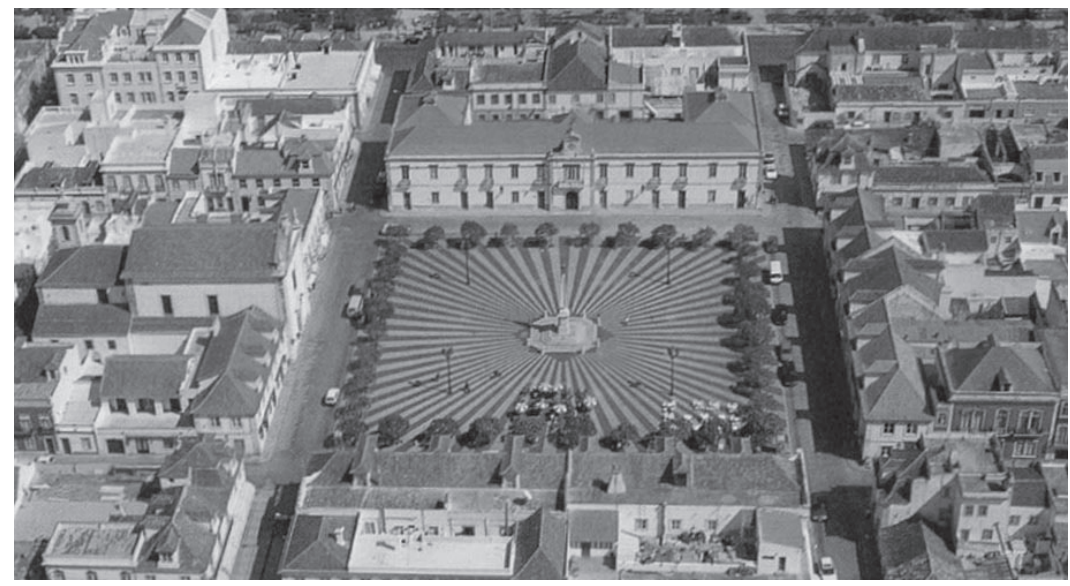

Fonte: www.emanseerden.babyhomepage.nl/fotoboek_categori.. - dez. 2005.

Desenvolvidos a partir do séc. XVII, os traçados urbanos - "Joaninos e Pombalinos" - multiplicam-sepelo Brasil. Uma análise das plantas de vilas e cidades concebidas ao longo desse período,comprova a adoção sistemática do modelo de praça formal, inserido na malha regular. Destaca-se como exemplo típico a cidade de Nova Vila de Portalegre, entre outras. 
Figura 11 - Nova Vila de Portalegre, 1772. Observa-se a presença da praça central, religiosa e cívica

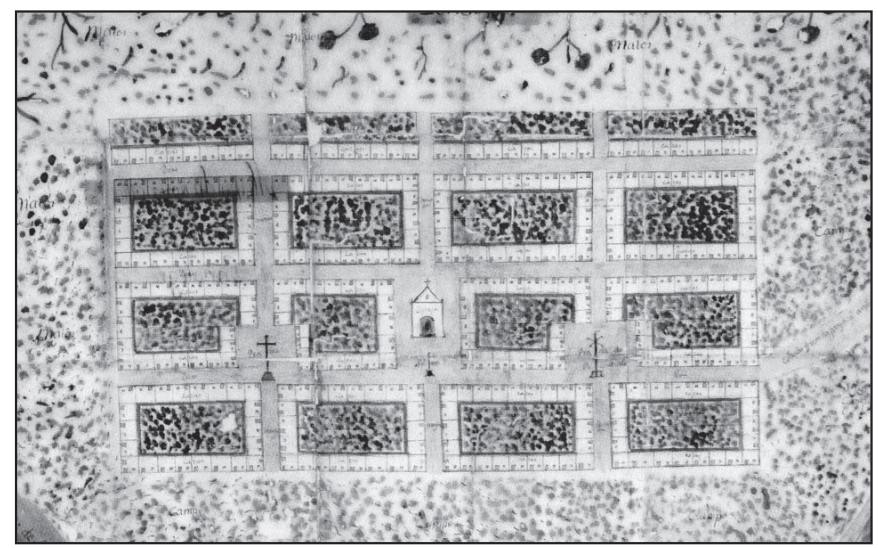

Fonte: Imagens de vilas e cidades do Brasil Colonial (REIS FILHO, 2000)

O traçado quadriculado comparece em muitas cidades, destacando a praça religiosa e a praça cívica (Pelourinho), como se observa abaixo nas plantas de Vila Viçosa, Vila Alcobaça e Vila de São João do Parnaíba.

Figura 12 - Vila Viçosa (1769) e Vila Alcobaça, Capitania de Porto Seguro, 1774, Brasil Traçado quadriculado, presença da praça religiosa e cívica (pelourinho)

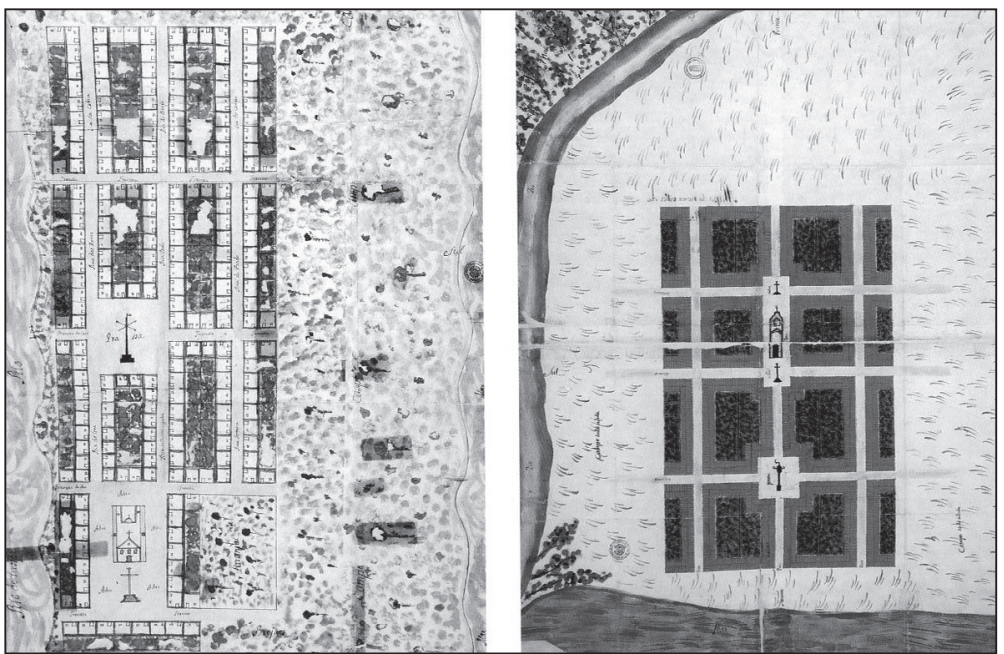

Fonte: Imagens de vilas e cidades do Brasil Colonial (REIS FILHO, 2000) 
Figura 13 - Planta da Vila de São João do Parnaíba, PIAUÍ, 1809

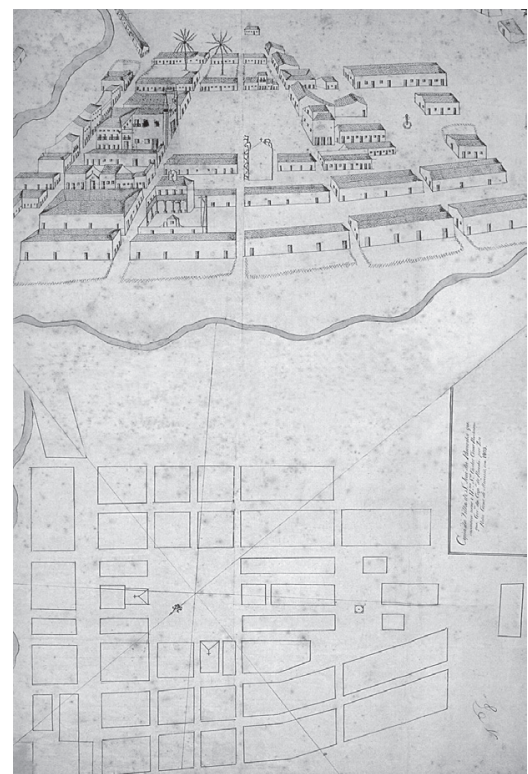

Praça formal da Matriz e do Pelourinho

Fonte: Imagens de vilas e cidades do Brasil Colonial (REIS FILHO, 2000).

O modelo de praça formal destaca-se na cidade colonial do Rio de Janeiro, cujo núcleo urbano se estabeleceu por volta de 1565. Ao longo do seu desenvolvimento, a cidade foi gradativamente definindo seus espaços públicos e edificando sua estrutura administrativa e religiosa: a Casa da Câmara e Cadeia, a Casa da Moeda, os Armazéns do Rei, e a Casa dos Governadores, o Convento do Carmo e a Ermida de Nossa Senhora do Ó. Um espaço se destacaria na paisagem, constituindo um belíssimo conjunto arquitetônico: o Largo do Carmo - primeira praça da várzea e centro da cidade colonial.

De modo semelhante à composição da Praça da Câmara de Salvador, o Largo reproduzia o modelo de espaço aberto retangular emoldurado pelas edificações administrativas. Espaço estratégico no traçado da cidade, o Largo do Carmo surgiu a partir da formação da Rua Direita, "quando a cidade recém-fundada desceu do morro do Castelo para se espraiar pela várzea entre este morro e o de São Bento". De início, era um espaço amplo, um grande vazio que foi se transformando em função dos edifícios que ali se instalaram (FERREZ, 1978, p. 9). 
Figura. 14 - Planta da cidade do Rio de Janeiro de João Massé, 1714. Em destaque o novo núcleo formado pela rua da misericórdia e direita, e pela praça central.

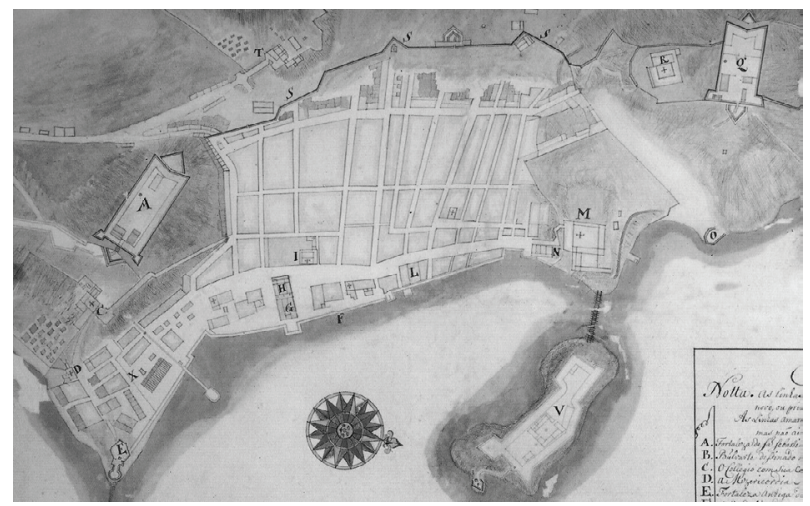

Fonte: Imagens de Vilas e Cidades do Brasil Colonial (REIS FILHO, 2000)

O status de sede administrativa da colônia, alcançado no séc. XVIII marcaria a instalação do poder secular no Largo, transformando sua função original: de espaço religioso, passa a abrigar também funções cívicas. A construção da Casa dos Governadores "contribuiu em definitivo para formalizar sua centralidade político-administrativa" e reafirmar seu papel como local símbolo da cidade colonial. Como atesta Sisson (2001, p. 2) “a centralidade do largo do Paço - elemento focal símbolo de um distrito, irradiando sobre este sua influência - deu-se então sobre duas unidades espaciais concêntricas, a cidade e o território para o qual o Rio de Janeiro era sede governamental”.

Com a vinda da Corte portuguesa para o Brasil, a cidade do Rio de Janeiro tornou-se a capital do reino, o que provocou alterações significativas no espaço principal da cidade: o Largo do Carmo. Edificações essenciais foram sendo ocupadas. De um lado, antigos marcos foram reforçados, e de outro, novos usos foram destinados. Sisson (2001, p. 3) comenta que o "Paço e prédios vizinhos [...] abrigaram o Príncipe Regente, família e comitiva. A Rainha-Mãe, seus criados e outros transmigrados alojaram-se no convento carmelita, para tal desocupado. A biblioteca Real [...] passou às dependências do hospital carmelita" e o mosteiro de São Bento tornou-se residência de fidalgos e servidores. O Palácio dos Governadores recebeu o título de Palácio Real e o Largo passou a sediar a residência oficial da 
família. A praça transformava-se no Paço Real (ou Paço Imperial), centro das manifestações e comemorações políticas imperiais: aclamações, batizados e desfiles.

\section{Figura. 15 - Revista Militar no Largo do Paço}

Pintura atribuída a Leandro Joaquim.

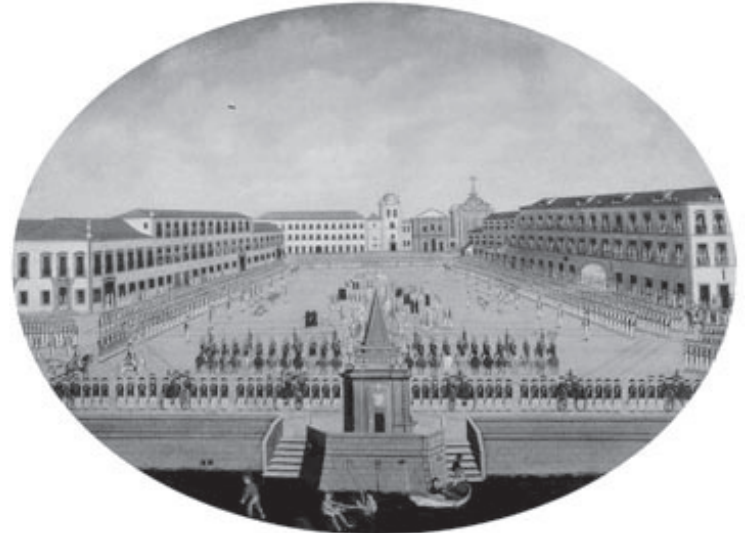

Fonte: Revista Oceanos (abr./jun., 2000)

A nova composição estética do Paço remete a outro importante território português: o Terreiro do Paço de Lisboa. Sua configuração espacial, como destaca Pereira (1996), apresenta uma semelhança notável à posição paisagística da praça brasileira.

Figura 16 - Paço Real, 1767.

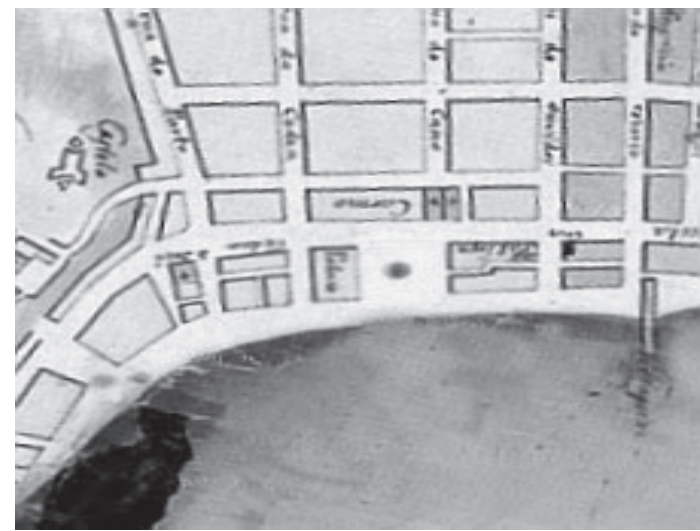

Fonte: Imagens de vilas e cidades do Brasil-Colonial (REIS FILHO, 2000). 
Figura 17 - Terreiro do Paço, atual Praça do Comercio, Lisboa.

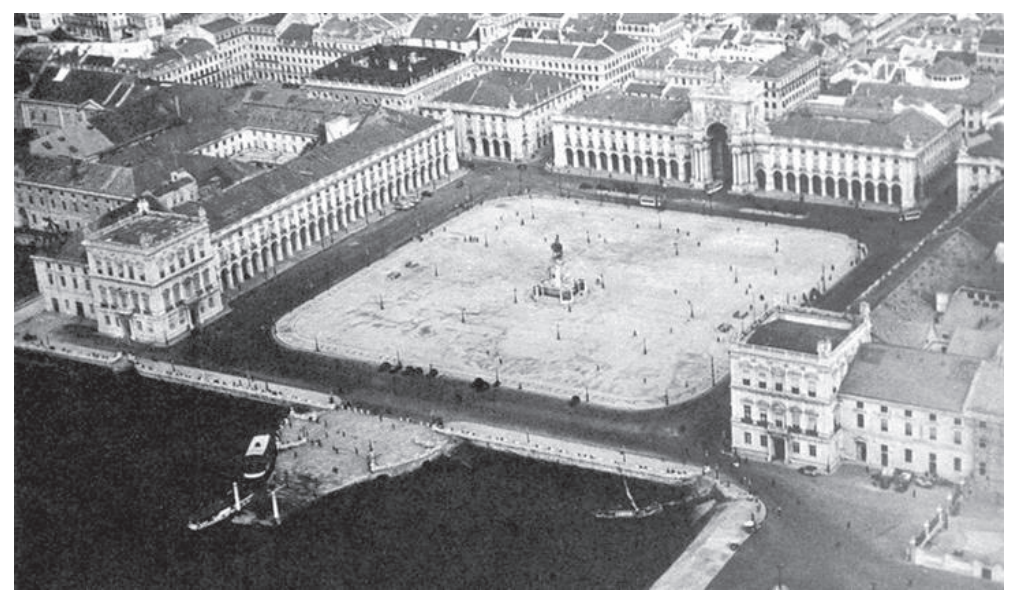

Fonte: Town and Square: from the Agora to the Village Green (ZUCKER, 1959)

\section{Considerações finais}

Os exemplos apresentados neste artigo demonstram a influência da tradição do urbanismo português na origem das praças coloniais brasileiras. Embora exista uma diversidade de praças que reproduzem os princípios urbanísticos aqui expostos, estes modelos de praça cívica e religiosa, existentes nas cidades de Salvador e Rio de Janeiro, sintetizam notadamente a transposição dos padrões da praça portuguesa. Essa influência resultou em uma maior diversidade na constituição dos espaços de praça no Brasil, se comparados à tradição espanhola.

Independentemente da vertente morfológica de origem, a característica fundamental observada no processo de formação das praças e dos conjuntos urbanos coloniais é sua multiplicidade de funções tais como o caráter cívico, religioso e comercial. É a partir dessa abordagem, consolidada na criação de diversos espaços para funções distintas, que a praça portuguesa deixou sua marca nas vilas e cidades ultramarinas da América. 


\title{
The colonial square in Brazil
}

\begin{abstract}
The main objective of this article is to investigate the origin of the Brazilian square, which is one of the main elements of the urban space. The starting point is the Portuguese colony era that happens simultaneously in many cities in the XV till XVII Century. This urban development process was marked by references of Portuguese urbanism and, in the case of the square, shows a diversity of models that still taken place in the urban landscape of the Brazilians' cities. In this context, the article analyzes specific cases that represent the development of the colonial square in Brazil, such as the first model of Brazilian civic square, in the city of Salvador, and the Real Paço, space-symbol of the Brazilian monarchy period, in the city of Rio de Janeiro. These squares, with its historical buildings, form a significant quantity and preserve the landscape of the colonial cities, allowing the citizens to understand its origin and its transformations in the last centuries. To study the trajectory of an urban space could not be reduced to a chronological exercise of urban events. The urban environment represents a space in constantly transformation, shaped as a "container" of successive symbolic layers. Therefore, to think about the square concept is also to rescue current symbols in our urban memory, that define space standards or that they point with respect to more frequent models.
\end{abstract}

Keywords: Square. Public space. Colonial cities.

\section{Referências}

CALDEIRA, Junia. A praça brasileira: trajetória de um espaço urbano: origem e modernidade. 2007. 423 f. Tese (Doutorado)-Departamento de História, IFCH, Universidade Estadual de Campinas, Campinas, 2007.

DELSON, Roberta. Novas vilas para o Brasil-Colônia: planejamento espacial e social no século XVIII. Brasília: Alva-Ciord, 1979. 
FERREZ, Gilberto. A Praça 15 de novembro antigo Largo do Carmo. Rio de Janeiro: RIOTUR, 1978.

FLEXOR, M. Helena; CAMARA, M. Paraguassu de A. A praça municipal da cidade de Salvador. In: TEIXEIRA, Manuel (Coord.). A praça na cidade portuguesa: colóquio Portugal-Brasil. Lisboa: Livros Horizontes, 2001.

PAIO, A. C. R. Praças nas novas vilas medievais, séculos XIII-XIV: estudo comparativo. In: TEIXEIRA, M. (Coord.) A praça na cidade Portuguesa. Colóquio Portugal-Brasil. Lisboa: Livros Horizontes, 2001.

PEREIRA, Sônia Gomes. A reforma urbana de Pereira Passos e a construção da identidade carioca. 1996. 240 f. Tese (Doutorado)-Escola de Belas Artes da UFRJ, Rio de Janeiro, 1996.

REIS FILHO, Nestor Goulart. São Paulo: vila cidade metrópole. São Paulo: FAPESP, CNPq, 2004.

REIS FILHO, Nestor Goulart. Imagens de vilas e cidades do Brasil Colonial. São Paulo: EDUSP, Imprensa Oficial do Estado, FAPESP, 2000.

REIS FILHO, Nestor Goulart. Evolução urbana do Brasil 1500/1720. São Paulo: Pini, 2000.

REIS FILHO, Nestor Goulart. Algumas experiências urbanísticas do início da República: 1890-1920. Cadernos de Pesquisa do LAP, São Paulo, n. 1, jul./ago. 1994. (Série Urbanização e Urbanismo).

REIS FILHO, Nestor Goulart. Notas sobre o urbanismo barroco no Brasil. Cadernos de Pesquisa do LAP, São Paulo, n. 3, nov./-dez. 1994. (Série Urbanização e Urbanismo).

ROSSA, Walter (Org.) Universo urbanístico português 1415-1822. Lisboa: Comissão Nacional para as Comemorações dos Descobrimentos Portugueses, 1998.

SANTOS, Paulo Ferreira. Formação de cidades no Brasil Colonial. Rio de Janeiro: UFRJ, 2001.

SISSON, R. Rio de Janeiro de D. João VI como etapa na formação da cidade contemporânea. Rio de janeiro, 2008. Disponível em: <http//: www.ihp.org.br/ docs/ress20000103.htm,2000-jan/2006>. Acesso em: 20 maio 2008. 
SOUZA, Gabriel Soares de. Tratado descritivo do Brasil em 1587. 3. ed. São Paulo: Cia. Editora Nacional, 1938.

TEIXEIRA, Manuel. Os modelos urbanos portugueses da cidade brasileira: colóquio a construção do Brasil urbano. Lisboa: Convento da Arrábida, 2000.

TEIXEIRA, Manuel (Coord.). A praça na cidade Portuguesa: colóquio PortugalBrasil. Lisboa: Livros Horizontes, 2001.

TIRAPELLI, Percival. Patrimônios da Humanidade no Brasil. São Paulo: Metalivros, 2001.

ZUCKER, P. Town and Square: from the Ágora to the Village Green. New York: Columbia University, 1959. 
